\title{
Endogenous Control Genes in Prostate Cells: Evaluation of Gene Expression Using 'Real-Time' Quantitative Polymerase Chain Reaction
}

\author{
Emmanuel Nna ${ }^{a} \quad$ Ibtisam E. Tothill ${ }^{a} \quad$ Linmarie Ludeman $^{b}$ Tracey Bailey ${ }^{a}$ \\ ${ }^{a}$ Cranfield Health, Cranfield University, Cranfield, and b Pathology Department, Cheltenham General Hospital, \\ Cheltenham, UK
}

\begin{abstract}
Key Words
Real-time quantitative polymerase chain reaction $\cdot$ Control genes - Gene expression - Transcript number - ABL1 • $\beta$-Glucuronidase $\cdot$ Glucose-6-phosphate dehydrogenase
\end{abstract}

\begin{abstract}
Objective: Our aims were to measure the level of expression of Abelson (ABL1), $\beta$-glucuronidase (GUS) and glucose-6phosphate dehydrogenase (G6PD) genes in exfoliated urine cells from healthy and transrectal ultrasound biopsy patients with elevated prostate-specific antigen levels and/or abnormal digital rectal examinations or urinary symptoms indicative of prostate problems, as well as in archived formalinfixed paraffin-embedded prostate materials. Materials and Methods: Real-time quantitative polymerase chain reaction (RQ-PCR) was used to evaluate the suitability of the 3 control genes, i.e. ABL1, GUS and G6PD, as control genes for prostate cancer cells. Exfoliated urine cells from 30 healthy males, 53 male patients, 138 cases of archived paraffin-embedded prostate tissues and 3 prostate cell lines were sampled. All cells were lysed in guanidine isothiocyanate buffer from which RNA was extracted and converted to CDNA by random hexamer priming. RQ-PCR was performed using TaqMan chemistries. Results: There was no significant difference in the level of expression for each of the 3 control genes in the cell lines. There was a significant difference in GUS transcript
\end{abstract}

level between patients and healthy controls in both urine and prostate tissue sections $(p<0.05)$. G6PD transcript numbers also differed significantly from those of GUS in the prostate cell lines and tissue sections $(p<0.05)$. The transcript numbers of all the control genes were significantly reduced in aged samples $(p<0.001)$. Conclusion: The ABL1 gene was the most stable control gene in both clinical specimens and cell lines. Therefore, we recommend its use to enable standardization and interlaboratory comparisons for the RQ-PCR of prostatic tumour markers.

Copyright @ 2010 S. Karger AG, Basel

\section{Introduction}

Real-time quantitative reverse transcription polymerase chain reaction (RQ-PCR) offers a highly sensitive tool for the accurate, reliable and reproducible quantification of gene expression $[1,2]$. It is now widely used in clinical molecular diagnostic laboratories to measure aberrant gene expression and/or gene fusions associated with tumours and infectious agents [3]. Several molecular markers are known to be variably associated with prostate cancer presence, progression, metastasis, risk of recurrence, prediction of treatment response and/or disease-free survival $[4,5]$. Currently, the only molecular assay licensed in the European Union for prostate cancer

\section{KARGER}

Fax +4161306 1234

E-Mail karger@karger.ch

www.karger.com
(C) 2010 S. Karger AG, Basel

1011-7571/10/0196-0433\$26.00/0

Accessible online at:

www.karger.com/mpp
Emmanuel Nna

Cranfield Health, Vincent Building, Cranfield University

Cranfield, Bedfordshire, MK43 0AL (UK)

Tel. +44 1234755 561, Fax +44 1234750875

E-Maile.nna@safetybiomedical.org 
diagnosis is the differential display 3 gene (DD3) assay also known as the PCA3 (prostate cancer antigen 3) assay and marketed as the PROGENSA ${ }^{\mathrm{TM}} \mathrm{PCA} 3$ assay [6]. This assay is normalised using prostate-specific antigen (PSA), which has a weak correlation with prostate malignancy. The reported sensitivity and specificity of the PCA3 assay (PCA3 score at a cut-off point of 35) was 58 and $72 \%$, respectively [7]. Although few studies have been conducted on the normalisation of prostatic tumour markers, there are no validated control genes applicable for clinical use. Some of the challenges are: (i) the choice of clinical specimen for molecular testing, (ii) the choice of suitable endogenous control gene(s) for validation and clinical use and (iii) a multicentre evaluation of the above factors.

Urine, serum and prostate biopsies are the main source of clinical specimens for the diagnosis of prostate disease. Nucleic acid-based testing on urine and serum samples may have a reduced sensitivity, especially for well-differentiated prostate carcinomas (low grades) that are organconfined with a low infiltration of malignant cells. Prostatic massage helps to increase the number of exfoliated urine cell sediments. However, in metastatic PCA, $>5$ cells per $7.5 \mathrm{ml}$ of blood are common, which is easily detectable by RQ-PCR [8]. Prostate tissues, either from radical prostatectomy, resection or transrectal ultrasound (TRUS)-guided biopsies are usually fixed for histology. Formalin fixation causes the defragmentation and degradation of nucleic acids. However, the primers for RQ-PCR are designed to amplify short sequences of gene targets (50-150 bp), and such amplicon sizes are available from fixed tissue sections $[9,10]$. Molecular profiling using these specimens may assist in the early detection of prostate cancer, risk stratification and the choice of intervention.

The second concern is the choice of suitable endogenous control genes. In 2006, Schmidt et al. [11] reported a quantitative multigene expression profiling of 9 prostate tumour markers using 4 control genes (GAPDH, HPRT, PBGD and TBP) to normalise the gene expression of target amplicons. The GAPDH gene is known to have 60 pseudogenes (www.pseudogenes.org/), which can result in the amplification of non-functional genomic DNA. PBGD has alternative transcriptional start sites [1], which can produce undetectable transcript variants. HPRT and TBP are also reported to have pseudogenes, and TBP shows a very low expression level which is tissue-dependent [1]. Nonetheless, in the study of Schmidt et al. [11] the TBP gene was chosen because it showed no differential expression between paired tumour and tumour-free samples. Many gene expression studies $[1,2]$ that are normalised using the $\beta$-actin (ACTB) gene even though it is known to have 8 pseudogenes (www.pseudogenes.org/) have been reported. Therefore, the choice of an endogenous control gene for normalising the transcript quantification of prostatic tumour markers is still a crucial issue and a consensus has yet to be reached. The use of a control gene in RQ-PCR informs regarding assay sensitivity and assesses sample quality and analytical reproducibility. This is achieved by the parallel amplification of the target gene and 1 or more control genes.

Three main criteria for selecting control genes are the absence of pseudogenes, a stable expression across different cell types in a tissue and little or no variation due to analytical processing [3]. A multi-centre evaluation is invaluable for ensuring that a standard protocol for RNA extraction, cDNA synthesis, primer design and reporting procedures is followed. Therefore, 3 candidate control genes, i.e. Abelson (ABL1), $\beta$-glucuronidase (GUS) and glucose-6-phosphate dehydrogenase (G6PD), were chosen for the evaluation of their suitability for the normalisation of prostate tumour markers in urine cell sediments and FFPE tissue sections. The 3 candidate control genes were chosen because they fulfilled the aforementioned criteria for selecting control genes.

\section{Subjects and Methods}

Thirty healthy male participants (mean age 52 years, PSA $<2.0$ $\mathrm{ng} / \mathrm{ml}$ and no history of prostate disease or urinary symptoms) were recruited at Cranfield University, and ethical approval was obtained from the Cranfield Health Research Ethics Committee. Fifty-three consecutive patients who attended the TRUS prostate biopsy section at Bedford Hospital were recruited, and ethical approval was obtained from the Bedfordshire Research Ethics Committee. One hundred and thirty-eight archived FFPE prostate tissue blocks were obtained from both Cheltenham and Gloucestershire hospitals, and favourable ethical approval was given by the Gloucestershire Research Ethics Committee. Details of the samples and clinical characteristics of the participants are contained in table 1.

\section{Prostate Cell Lines and Steroid Hormones}

PNT1A and PC-3 cell lines [from the European Collection of Cell Cultures (ECACC), UK] and an MDAPCA 2 b cell line [from the American Type Culture Collection (ATCC), USA] were grown in appropriate culture media. The PNT1A cells were grown in RPMI 1640 medium supplemented with $10 \%$ (v/v) foetal calf serum (FCS), a $1 \%(\mathrm{v} / \mathrm{v})$ penicillin-streptomycin mixture (Sigma, UK) and $0.1 \%(\mathrm{v} / \mathrm{v})$ Amphotericin B (Sigma). The PC-3 and MDAPCA 2 b cells were grown in DMEM: F12 supplemented with the same additives. For stimulation experiments, the cell lines were weaned in phenol-free media types supplemented with dextran charcoal-treated FCS (DCC-FCS) (Perbio, UK). The cells 
Table 1. Descriptive characteristics of participants and samples

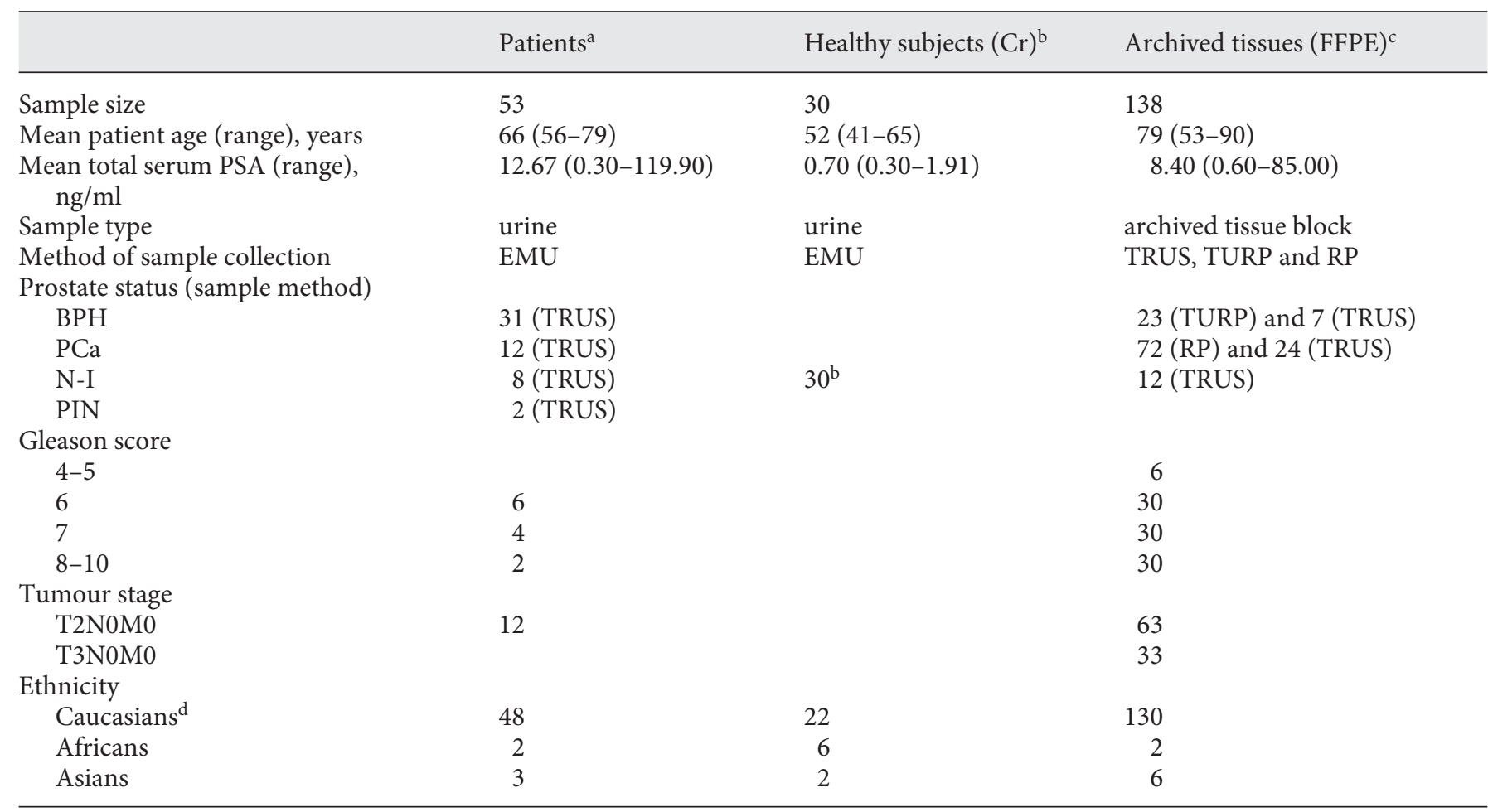

TURP $=$ Transurethral resection of the prostate; $\mathrm{PCa}=$ prostate carcinoma; $\mathrm{RP}=$ radical prostatectomy; $\mathrm{N}-\mathrm{I}=$ non-involved (no case of malignancy or BPH); PIN = prostatic intraepithelial neoplasia; $\mathrm{EMU}=$ early-morning urine without prostatic massage; $\mathrm{Cr}=$ control group.

a Patients referred to the urologic clinic due to a raised PSA and/or an abnormal digital rectal examination. They underwent a TRUS biopsy as part of their medical care.
${ }^{\mathrm{b}}$ Healthy subjects did not undergo any biopsy; they were chosen based on a history of no prostate problems and a normal PSA, i.e. a total PSA $<2.5 \mathrm{ng} / \mathrm{ml}$.

${ }^{\mathrm{c}}$ Medical records of patients whose archived tissue blocks were sampled.

d British whites. were harvested at the exponential phase for stimulation experiments. The steroids, i.e. $17 \beta$-oestradiol, hydrocortisone, $5 \alpha$-androstane-17 $\beta$-3-one (dihydrotestosterone) and testosterone were purchased from Sigma. All of them were first dissolved in DMSO to a working concentration of $2 \mathrm{mM}$. Serial dilutions were later made using DCC-FCS-supplemented media for growth inhibition assays.

\section{Dose- and Time-Dependent Stimulations}

The inhibition concentrations (ICs) of steroid hormones were first determined using a colorimetric sulphorhodamine assay, which has been described in detail previously [12]. The $\mathrm{IC}_{10}$ and $\mathrm{IC}_{50}$ values of the steroid hormones were then used to stimulate the cell lines for 12-, 24-, 48- and 72-hour periods. Briefly, $10^{6}$ cells were seeded into each well of a 12-well plate and grown for $12 \mathrm{~h}$ at $37^{\circ} \mathrm{C}$ with $5 \% \mathrm{CO}_{2}$ to allow for attachment; hormones were added as well. For each prostate cell line, 2 different doses of the four steroid hormones, i.e. $\mathrm{IC}_{10}$ and $\mathrm{IC}_{50}$ doses, were used for the four time intervals $(12,24,48$ and $72 \mathrm{~h})$, two controls - DMSO treated and no treatment - culture media only were included in all the intervals (resulting in 48 samples of which 16 where controls). The cells were trypsinised and washed in sterile PBS and cell pellets were lysed in $1.0 \mathrm{ml}$ of guanidine isothiocyanate (GITC) buffer (350 $\mu \mathrm{l}$ of which was used for RNA extraction).

\section{Clinical Samples}

The participants voided $20 \mathrm{ml}$ of early morning urine without prostatic massage. Within $6 \mathrm{~h}$ of sample collection, the urine samples were centrifuged at $1,840 \mathrm{~g}$ for $10 \mathrm{~min}$, decanted and the cell sediments were washed in $15 \mathrm{ml}$ of sterile PBS (Invitrogen, UK). Cell pellets were lysed in $350 \mu$ l of GITC buffer for RNA extraction. About $5 \mathrm{ml}$ of venous blood was collected from each of the healthy males (control group) and patients using standard venepuncture techniques. Serum was harvested and serum PSA measured using a Microwell ELISA kit from Diagnostic Automation, Inc., Calabasas, Calif., USA. Tissue blocks were chosen based on pathology reports. The selected samples were: 30 cases of nodular hyperplasia [benign prostatic hyperplasia (BPH)], 96 cases of prostate cancer and 12 cases of non-involved prostate tissueschronic inflammation, no dysplasia and no carcinoma (table 1). 
Table 2. Primer and probe sets for RQ-PCR

\begin{tabular}{|c|c|c|c|c|}
\hline \multirow{2}{*}{$\begin{array}{l}\text { Gene } \\
\text { ABL1 }\end{array}$} & \multicolumn{2}{|c|}{ Sequence primer $5^{\prime}-3^{\prime}$} & \multirow{2}{*}{$\begin{array}{l}\text { Chromosome } \\
\text { location }\end{array}$} & \multirow{2}{*}{$\begin{array}{l}\text { Amplicon } \\
\text { size, bp }\end{array}$} \\
\hline & $\begin{array}{l}\text { Forward: } \\
\text { Reverse: } \\
\text { Probe: }\end{array}$ & $\begin{array}{l}\text { GATACGAAGGGAGGGTGTACCA } \\
\text { CTCGGCCAGGGTGTTGAA } \\
\text { FAM-GCTTCTGATGGCAAGCTCTACGTCTCCT-TAMRA }\end{array}$ & & \\
\hline GUS [2] & $\begin{array}{l}\text { Forward: } \\
\text { Reverse: } \\
\text { Probe: }\end{array}$ & $\begin{array}{l}\text { GAAAATATGTGGTTGGAGAGCTCATT } \\
\text { CCGAGTGAAGATCCCCTTTTTA } \\
\text { FAM-CCAGCACTCTCGTCGGTGACTGTTCA-TAMRA }\end{array}$ & $7 q 21$ & 60 \\
\hline G6PD & $\begin{array}{l}\text { Forward: } \\
\text { Reverse: } \\
\text { Probe: }\end{array}$ & $\begin{array}{l}\text { GGCGATGCCTTCCATCAG } \\
\text { CCAGGTCACCCGATGCA } \\
\text { TET-CGGATACACACATATTC-NQF }\end{array}$ & $\mathrm{Xq} 28$ & 63 \\
\hline KLK2 & $\begin{array}{l}\text { Forward: } \\
\text { Reverse: } \\
\text { Probe: }\end{array}$ & $\begin{array}{l}\text { TGCCCATTGCCTAAAGAAGAATAG } \\
\text { CCTGTGTCTTCAGGCTCAAACA } \\
\text { TET-CTGGGTCGGCACAAC-TAMRA }\end{array}$ & $19 \mathrm{q} 13$ & 72 \\
\hline
\end{tabular}

$\mathrm{NQF}=$ Non-fluorescent quencher in a minor groove binding probe .

Only tissue blocks with the worst lesions of their category as marked in the corresponding HE slides were sampled for microtomy. The tissue sections were macrodissected. Two pieces of 25 - $\mu \mathrm{m}$-thick sections were cut using decontaminated microtome blades, picked onto slides and macrodissected into $2 \mathrm{ml}$ tubes. The tubes were briefly centrifuged and then deparaffinised in 2 washes of $1 \mathrm{ml}$ xylene for $10 \mathrm{~min}$ each; the xylene was decanted and the tissue rehydrated by 2 washes in $1 \mathrm{ml}$ of $100 \%$ ethanol before allowing the pellets to dry for $5 \mathrm{~min}$ on a dry heat block kept at $37^{\circ} \mathrm{C}$. The tissue pellets were digested overnight in $540 \mu \mathrm{l}$ of ATL tissue lysis buffer and $60 \mu \mathrm{l}$ of proteinase K (Qiagen, UK). The digest was centrifuged for $5 \mathrm{~min}$ and the supernatant (containing nucleic acids) was collected. $350 \mu$ l of the supernatant was used for RNA extraction.

\section{RNA Extraction and cDNA Synthesis}

For all samples, $350 \mu \mathrm{l}$ of the cell or tissue lysate was used for RNA extraction using a spin column RNeasy Mini kit (Qiagen). The elution volume was $60 \mu \mathrm{l}$ (50 $\mu$ l of which was used for cDNA synthesis). RNA quality was checked using a BioRad automated electrophoresis system. The average 28S/18S RNA ratio was 1.75 (range 1.60-1.95). The amount of RNA used for cDNA synthesis ranged from 0.7 to $3 \mu \mathrm{g}$. An equal volume of RNA elution was used in cDNA synthesis. Random primers (at a final concentration of $300 \mathrm{ng}$ per reaction) from Invitrogen, UK, were used for cDNA synthesis using the Moloney murine leukaemic virus reverse transcriptase (Invitrogen) and RNasin (an RNase inhibitor; Promega, UK). The cDNA synthesis was done immediately after RNA extraction.

\section{Real-Time PCR Set-Up}

TaqMan chemistries were used in the BioRad CFX96 real-time PCR platform. The sequences of the primers and probes are shown in table 2. FAM dye was used for ABL1 and GUS, and TET dye for G6PD. For absolute quantification, stable calibrators were used to construct standard curves for reading samples. The ABL1 and G6PD plasmid standards were kind gifts from the laboratory of Dr. Letizia Foroni (Imperial College, London, UK). GUS plasmid was purchased from Ipsogen, Marseille, France. The plasmids were used at $10^{1}, 10^{2}, 10^{3}, 10^{4}, 10^{5}$ and $10^{6}$ copies per $2.5 \mu \mathrm{l}$. The number of PCR cycles at which the relative fluorescent signal intensity of a sample or calibrator crosses the threshold line is known as the $\mathrm{Ct}$ value [cycle of threshold also known as cycle of quantification $(\mathrm{Cq})]$ and this value is inversely proportional to the starting quantity of the target transcript. Five technical parameters for accepting valid RQ-PCR results were obtained from the following standard curves and amplification plots: (i) the slope of the standard curve which determines PCR efficiency (E) and is related by the formula $\mathrm{E}=10^{\text {(-1/slope) }}-1$, (ii) the correlation coefficient $\left(\mathrm{R}^{2}\right.$ value) which is a measure of the relationship between the $\mathrm{Ct}$ value and the log of the starting quantity of the target for a given standard curve, (iii) the y-intercept of the standard curve which is the Ct value that corresponds to a copy of the target molecule, (iv) the difference in the Ct values of duplicate measures $(\Delta \mathrm{Ct})$ and $(\mathrm{v})$ the relative fluorescence unit plateau value which is the maximal normalised fluorescent signal at the PCR plateau. The threshold value and baseline were auto-set.

Normalised relative quantification (NRQ) was done for the $\mathrm{KLK} 2$ gene using the formula $\mathrm{NRQ}=\mathrm{E}^{\mathrm{Ct} \mathrm{KLK} 2} / \mathrm{E}^{\mathrm{Ct} \mathrm{ABL} 1}[13]$. cDNA from the PNTIA cell line was diluted in tRNA in TE buffer for determining $\mathrm{E}$ for the KLK2 quantification. The KLK2 gene is a prostate-specific tissue kallikrein whose protein product (hK2) is a putative prostate tumour marker $[14,15]$. The TaqMan Universal $2 \times$ Master Mix, primers and TaqMan probes were purchased from Applied Biosystems, UK. The thermal profile for the TaqMan assay was $50^{\circ} \mathrm{C}$ for $2 \mathrm{~min}$, an initial denaturation at $95^{\circ} \mathrm{C}$ for $10 \mathrm{~min}$, a cycle denaturation of $95^{\circ} \mathrm{C}$ for $15 \mathrm{~s}$, and annealing and extension at $60^{\circ} \mathrm{C}$ for $1 \mathrm{~min}$ for 40 cycles. Data was acquired at all stages. 
Statistical Analysis

The D'Agostino-Pearson omnibus normality test was performed on the data sets, and Kruskal-Wallis and Dunn's multiple comparisons tests were performed for the analysis of variance (ANOVA). GraphPad Prism version 4.02 software (www. graphpad.com) was used.

\section{Results}

The $\mathrm{IC}_{10}$ and $\mathrm{IC}_{50}$ values for oestradiol were 4.92 and $33.96 \mu \mathrm{M}$; for dihydrotestosterone, 0.86 and $8.44 \mu \mathrm{M}$; for testosterone, 7.63 and $30.42 \mu \mathrm{M}$; and for hydrocortisone, 4.64 and $261.9 \mu \mathrm{M}$, respectively. These concentrations were used in stimulating the cell lines.

From the amplification plots and standard curves (not shown), our slope range was -3.30 to $-3.60, \mathrm{R}^{2}$ values were $>0.99$, the $y$-intercept was $\leq 40$, the $\Delta$ Ct was $<1.0$ and the relative fluorescence at plateau value was consistently $\leq 1,000$.

The transcript levels of ABL1 in the FFPE prostate tissue sections are shown in figure 1a. In the cell lines the median value of ABL1 copies was $1.72 \times 10^{4}$ (range 3.62 $\times 10^{0}$ to $2.22 \times 10^{5}$ ) while in the clinical specimens it was $2.75 \times 10^{1}\left(\right.$ range $1.67 \times 10^{0}$ to $\left.2.42 \times 10^{4}\right)$. There was no significant difference in the ABL1 transcript copies when cell lines were compared to one another or when the clinical samples were compared to one another.

The GUS transcript number in the FFPE prostate tissue sections is shown in figure $1 \mathrm{~b}$. The median values of GUS copies were $1.44 \times 10^{4}$ (range $6.15 \times 10^{0}$ to 1.56 $\left.\times 10^{5}\right)$ in the cell lines and $2.67 \times 10^{1}\left(\right.$ range $1.17 \times 10^{0}$ to $\left.4.42 \times 10^{4}\right)$ in the clinical samples. There was a significant difference $(p=0.04)$ in the GUS quantity between the prostate cancer cases and the non-involved cases.

The median value of the G6PD transcript number was $4.76 \times 10^{4}$ (range $1.71 \times 10^{0}$ to $\left.5.91 \times 10^{5}\right)$ in the cell lines and $3.34 \times 10^{1}$ (range $2.31 \times 10^{0}$ to $\left.2.67 \times 10^{3}\right)$ in the clinical samples. There was no significant difference in the G6PD copies in the 3 cell lines (when compared to one another) and there was no significant difference in the clinical samples. But the transcript number of G6PD differed significantly from those of GUS in the cell lines and prostate tissue sections $(\mathrm{p}<0.05)$.

The mean value of the ABL1 transcript number was related to that of GUS by a ratio of 1.19 and to that of G6PD by a ratio of 0.36 in the cell lines, and by ratios of 1.03 and 0.82 , respectively, in the clinical samples. Conversely, the mean value of the G6PD transcript number related to that of GUS by a ratio of 3.30 and to that of
ABL1 by a ratio of 1.25 in the cell lines. The mean ABL1 transcript number lies between those of GUS and G6PD.

The transcript levels of all the control genes in the exfoliated urine cells of healthy males $(n=30)$ and the patient group who attended the TRUS-guided prostate biopsy section $(n=53)$ are given in figure 1c. The GUS transcript number differed significantly between the healthy controls and the patient group $(\mathrm{p}<0.05)$. The serum PSA levels of the healthy controls, TRUS biopsy patients and FFPE cases are given in figure 1d. Only 6 (4.3\%) FFPE patients had a PSA level $<2.50 \mathrm{ng} / \mathrm{ml}, 5$ of whom were $\mathrm{BPH}$ cases and 1 of whom was a chronic inflammation case. In the TRUS biopsy cohort, only 1 patient (a non-involved case) had a PSA level $<2.50 \mathrm{ng} / \mathrm{ml}$. There was a significant difference in serum PSA between the healthy controls and the TRUS biopsy patients $(\mathrm{p}<0.001)$ and between the healthy controls and the FFPE cases $(\mathrm{p}<0.001)$.

The NRQ of KLK2 in the clinical specimens is shown in figure 1e. There was no difference in the NRQ of KLK2 determined using ABL1 alone compared to that determined using the geometric mean of the 3 control genes. The normalised KLK2 transcript level was significantly lower in benign and malignant cases compared to healthy controls $(\mathrm{p}<0.05)$. KLK2 is a prostate-specific tissue kallikrein.

The effect of sample age on ABL1 transcript copies in archived FFPE tissue materials for all cases (normal, BPH and prostate cancer) is shown in figure 1f. There was a significant difference in ABL1 copies between cases from 2006-2007 and 2008 samples ( $\mathrm{p}<0.001)$. Aged samples had a reduced ABL1 transcript number. Similar results were obtained for GUS and G6PD (data not shown).

\section{Discussion}

Crucial for the routine use of RQ-PCR for diagnostic pathology is the choice of control genes for normalising results and quality control. The ABL1, GUS and G6PD genes were expressed in all the samples. G6PD and ABL1 gene expressions were more stable than that of GUS in different prostate specimen types but G6PD and GUS differed significantly. Previous reports $[1,2]$ showed that ABL1 transcript numbers were more stable than those of GUS in leukaemic blood samples. Unlike other prostate control genes, i.e. GAPDH, HPRT, PBGD, TBP, $18 \mathrm{~S}$ rRNA and $\mathrm{ACTB}$ previously reported $[1,10,11]$, the ABL1 gene has no known pseudogenes. In this study, the ABL1 transcript number showed no significant variation between 

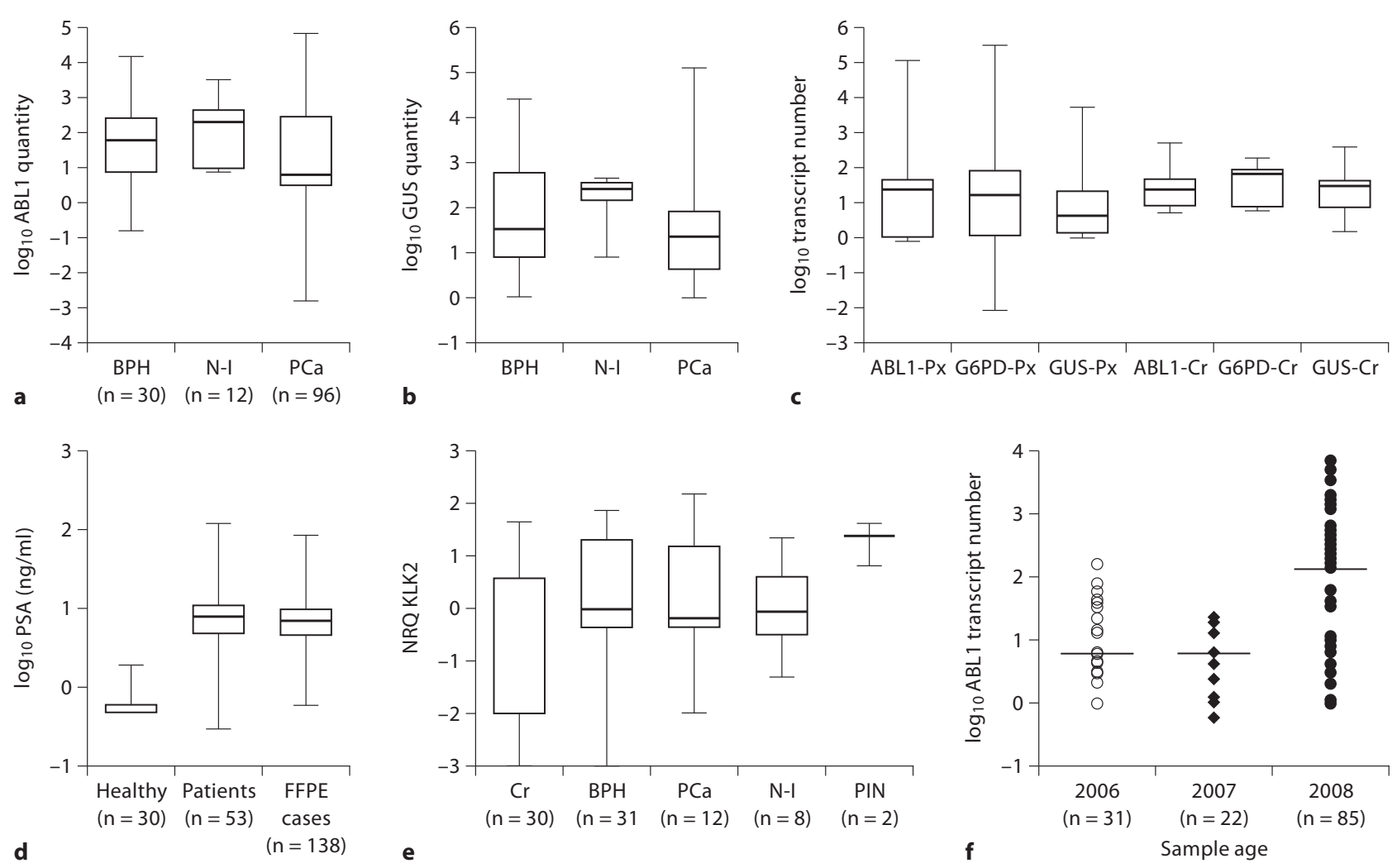

Fig. 1. Transcript levels of control genes and a target gene (KLK2). a ABL1 transcript quantity in FFPE prostate tissue sections. Similar results were obtained for G6PD. N-I = Non-involved cases (cases of inflammation or no detectable lesion); $\mathrm{PCa}=$ prostate cancer. b GUS transcript quantity in FFPE prostate sections. There was a significant difference in transcript number between prostate cancer cases and non-involved cases ( $p<0.05$, KruskalWallis test). c Transcript levels of ABL1, G6PD and GUS in the exfoliated urine cells of patients and healthy males (control group). There was also a significant difference in GUS transcript number between patients and healthy controls $(\mathrm{p}<0.05$, KruskalWallis test). $\mathrm{Px}=$ Patients; $\mathrm{Cr}=$ control group. $\mathbf{d}$ Serum PSA in the healthy control group, prospective patients and archived FFPE

prostate tumour and tumour-free samples. The relative ratio of ABL1 to GUS and of ABL1 to G6PD was similar in both the cell lines and the clinical samples. ABL1 was the most stable of the 3 control genes in terms of expression level (transcript number). Its transcript number correlated with the cell number in different specimen types. A comparison of the control genes' transcript numbers in aged FFPE tissues showed that more recently processed samples (2008 cases) were significantly better than older samples for normal, BPH and prostate cancer cases $(\mathrm{p}<$ 0.001) (fig. 1f). Another comparison showed that sample cases (PSA values for FFPE cases were based on clinical notes at the time of referral). PSA was significantly lower in the control group ( $p<0.05$, Kruskal-Wallis test). e NRQ of KLK2 in the exfoliated urine cells of the patients and healthy controls. There is no significant difference. The NRQ of KLK2 was significantly lower in the patient group (benign and malignant cases) compared to the healthy subjects $(\mathrm{p}<0.05)$. PIN $=$ Prostatic intraepithelial neoplasia. $f$ Sample age affected the transcript levels of the control genes. Most recently processed FFPE samples for all cases (normal, BPH and prostate cancer) had a significantly higher ABL1 value compared to 1- and 2-year-old samples. Similar results were obtained for GUS and G6PD.

handling (oestradiol treatment) affected the control gene level. Higher doses of oestradiol caused a significant reduction $(\mathrm{p}<0.01)$ in the copies of control genes due to a reduced cell number (data not shown). Therefore, the ABL1 gene was much better than previously reported control genes.

Biologically, the regulation of housekeeping genes reflects variations in normal cellular activities. The decrease in the control gene transcript number as a result of poor sample quality necessitates a consensus cut-off value for assessing sample quality in both the exfoliated 
urine cells and the FFPE materials. There is a requirement to establish baseline values for the ABL1 transcript number in both specimen types [16]. Conventionally, $10^{4}$ copies of ABL1 per $2.5 \mu \mathrm{l}$ cDNA is accepted as a consensus cut-off value for good sample quality $[3,16]$. However, this cut-off point was determined with blood samples. Currently there is no consensus cut-off value for prostate tissues. By using ABL1 as a stable control gene for prostate tissue, a cut-off value could be established from various laboratories using large sample sizes. The control gene level affects RQ-PCR assay sensitivity; therefore, the interpretation of results must be treated with caution when the control gene level is reduced. The primary task is to establish the ABL1 transcript number at which an FFPE material may be considered a good sample for the RQPCR of prostatic tumour markers with the same criteria affecting tests done on exfoliated urine cells with or without prostatic massage. Another point is the adherence to a set of analytical guidelines such as, for example, the 5 parameters for assessing a valid RQ-PCR as reported in the Results section. In addition, it is important that a standard protocol for RNA extraction, cDNA synthesis and reporting guidelines also be adhered to [16]. A single control gene (ABL1) facilitates the inter-laboratory comparison of results, which is of paramount importance to the clinical use of molecular diagnostics. However, control samples which can be used across different laboratories would also ensure compliance with good laboratory practice [16]. Our study supports the use of the ABL1 control gene for future validations. The normalisation of molecular tests for genes such as TMPRSS2 fusion genes, PSA, AR, oestrogen receptors, PCA 3 and CD44 using the ABL1 gene may assist the diagnosis, risk stratification and prognostication of prostate tumours.

\section{Conclusions}

Our study showed that of the 3 control genes (ABL1, GUS and G6PD), ABL1 was the most stable in both clinical specimens and cell lines; hence, we recommend ABL1 for further validation and use in the normalisation of the RQ-PCR of prostatic tumour markers. It has no known pseudogenes. Further studies are required to establish cut-off points for assessing sample quality in both FFPE materials and exfoliated urine cells.

\section{References}

1 Beillard E, Pallisgaard N, van der Velden VH, Bi W, Dee R, van der Schoot E, Delabesse E, Macintyre E, Gottardi E, Saglio G, Watzinger F, Lion T, van Dongen JJ, Hokland P, Gabert $\mathrm{J}$ : Evaluation of candidate control genes for diagnosis and residual disease detection in leukemic patients using 'real-time' quantitative reverse-transcriptase polymerase chain reaction (RQ-PCR) - a Europe Against Cancer program. Leukemia 2003;17:1-13.

-2 Gabert J, Beillard E, van der Velden VH, Bi W, Grimwade D, Pallisgaard N, Barbany G, Cazzaniga G, Cayuela JM, Cave H, Pane F, Aerts JL, De Micheli D, Thirion X, Pradel V, González M, Viehmann S, Malec M, Saglio G, van Donge JJ: Standardization and quality control studies of 'real-time' quantitative reverse transcriptase polymerase chain reaction of fusion gene transcripts for residual disease detection in leukemia - a Europe Against Cancer program. Leukemia 2003; 17: 2318-2357.

3 Kaeda J, Chase A, Goldman JM: Cytogenetic and molecular monitoring of residual disease in chronic myeloid leukaemia. Acta Haematol 2002;107:64-75.

4 Isaacs JT: Molecular markers for prostate cancer metastasis: developing diagnostic methods for predicting the aggressiveness of prostate cancer. Am J Pathol 1997;150:15111520.

-5 Quinn ID, Henshall SM, Sutherland RL: Molecular markers of prostate cancer outcome. Eur J Cancer 2005;41:858-887.

6 Agrawal S, Dunsmuir WD: Molecular markers in prostate cancer. 1. Predicting lethality. Asian J Androl 2009;11:14-21.

7 Leonard SM, Fradet Y, Deras IL, Blasé A, Mathis J, Sheila M, Aubin J, Cancio AT, Desaulniers M, Ellis WJ, Rittenhouse H, Groskopf J: PCA3 molecular urine assay for prostate cancer in men undergoing repeat biopsy. Urology 2007;69:532-535.

$\checkmark 8$ Corey E, Arfman EW, Oswin MM, Melchior SW, Tindall DJ, Young CY, Ellis WJ, Vessella RL: Detection of circulating prostate cells by reverse transcriptase-polymerase chain reaction of human glandular kallikrein $(\mathrm{Hk} 2)$ and prostate-specific antigen (PSA) messages. Urology 1997;50:184-188.

$\checkmark 9$ Gillio-Tos A, De Marco L, Fiano V, GarciaBragado F, Dikshit T, Boffetta P, Merletti F: Efficient DNA extraction from 25-year-old paraffin-embedded tissues: study of 365 samples. Pathology 2007;39:345-348.

10 Antonov J, Goldstein DR, Oberli A, Baltzer A, Pirotta M, Leischmann A, Altermatt HJ, Jaggi R: Reliable gene expression measure- ments from degraded RNA by quantitative real-time PCR depend on short amplicons and a proper normalization. Lab Invest 2005; 85:1040-1050.

11 Schmidt U, Fuessel S, Koch R, Baretton GB, Lohse A, Tomasetti S, Unversucht S, Froehner M, Wirth MP, Meye A: Quantitative multi-gene expression profiling of primary prostate cancer. Prostate 2006;66:1521-1534.

12 Vichai V, Kirtikara K: Sulforhodamine B colorimetric assay for cytotoxicity screening. Nat Protoc 2006;1:1112-1116.

13 Pfaffl MW: A new mathematical model for relative quantification in real-time RT-PCR. Nucleic Acids Res 2001;29:2002-2007.

14 Diamandis EP, Obiezu CV: Mini-review: human tissue kallikrein gene family: applications in cancer. Cancer Lett 2005;224:1-22.

15 Benedettini E, Nguyen P, Loda M: The pathogenesis of prostate cancer: from molecular to metabolic alterations. Diagn Pathol 2008;14:195-201.

16 Bustin SA, Benes V, Garson JA, Hellemans J, Huggett J, Kubista M, Mueller R, Nolan T, Pfaffl MW, Shipley GL, Vandesompele J, Wittwer CT: The MIQE guidelines: minimum information for publication of quantitative real-time PCR experiments. Clin Chem 2009;55:611-622. 